Research Article

\title{
Hybrid Natural and Forced Active Balancing Control of Battery Packs State of Charge Based on Partnership for a New Generation of Vehicles
}

\author{
Yewen Wei $\mathbb{D},{ }^{1,2}$ Shuailong Dai $\mathbb{D}^{1,2}$ Jiayu Wang, ${ }^{1}$ Zhifei Shan, ${ }^{1}$ and Jie Min ${ }^{1}$ \\ ${ }^{1}$ College of Electrical Engineering \& New Energy, China Three Gorges University, Yichang, China \\ ${ }^{2}$ Hubei Province Collaborative Innovation Center for New Energy Microgrid, CTGU, Yichang, China \\ Correspondence should be addressed to Shuailong Dai; daishuailong@126.com
}

Received 15 September 2018; Revised 5 November 2018; Accepted 8 November 2018; Published 4 December 2018

Academic Editor: Pascal Venet

Copyright (c) 2018 Yewen Wei et al. This is an open access article distributed under the Creative Commons Attribution License, which permits unrestricted use, distribution, and reproduction in any medium, provided the original work is properly cited.

Battery packs are widely used in electric vehicles, and their state-of-charge is one of the essential issues that affect the performances, whilst the balance between parallel and series cell of the battery pack always has an obvious effect. To enhance the working performance of the lithium-based power battery pack, a hybrid natural and forced active balancing control (HNFABC) strategy is proposed and adopted to the balancing circuit that is proposed in this work. These converters, which are advantageous in natural balancing and forced equalization, accelerate the balance speed of natural equilibrium in the final stage and protect the battery from being repeatedly charged and discharged. Simulation and experimental results show that HNFABC is not only simpler than other traditional balance control strategies but also faster in the equalization process. The idea of combining natural equilibrium and forced equilibrium can be inspired to be used in some related industries.

\section{Introduction}

With the gradual deterioration of the global natural environment, new energy electric vehicles have attracted wide attention and are gradually applied around the world due to their environmental friendliness and can be used as controllable loads in close cooperation with power grids and charging stations [1-3]. In these electric vehicles, batteries are generally needed for energy and power storage. However, the inconsistency of individual cells in the battery pack leads to a reduction in overall charge and discharge performance [4-7]. Therefore, various balanced topologies and control strategies have been proposed to reduce battery inconsistencies.

In [8], to reduce the switching loss and overcome the overvoltage problem, a zero-voltage switch and zero-current switch circuit topology based on DCM operation was proposed. However, the interleaving technique proposed requires a sixteen-channel PWM control signal fulfilling the balancing requirement. In [9], Lee et al. proposed a modular equilibrium idea, in which the system consists of $N$ batteries and $M$ equalization modules. The circuit structure is complex, and it is necessary to adjust the state of twelve switching tubes to achieve the primary energy balance. In [10], the circuit is based on a time-sharing flyback converter. Each cell shares an equalization module in the control gap of the lowpower microcontroller. However, transformer equalization increases the weight and volume of the equalization circuit to a certain extent. In [11], a new type of switching circuit that does not require voltage detection was proposed. In order to use the single-charge equalizer of the multiwinding transformer, the energy balancing between the cells is achieved by the magnetization energy of the multiwinding transformer, which causes a large amount of magnetic loss inevitably. In [12], the idea of energy sharing was used to adaptively adjust the charge and discharge rates of all batteries while maintaining the DC bus voltage, which solved the unbalancing problems of SOC between battery pack cells. Using a low-power DC, power converter may take a long time to achieve equilibrium. In [13], this paper aimed at 
solving this problem by using a buck chopper and an adaptive unscented Kalman algorithm for estimating the state-of-charge (SOC) of batteries. The scheme in the work presents a simple circuit structure, and shows a faster response compared with traditional methods, while a four-cell balancing experiment is provided. However, this technology is difficult to be applied when the number of battery cells increases. As closed-loop, online SOC estimation methods, Kalman filter (KF) and other observer-based algorithms have gained growing attention from both academia and industry. Nowadays, extended Kalman filtering (EKF) [14] and sigma-point Kalman filtering, i.e., central difference Kalman filter (CDKF) or unscented Kalman filter (UKF) [15], based on equivalent circuit models (ECMs), were applied. To make physical meanings of model parameters and more insights into internal electrochemical reactions, various electrochemical models were also combined with these filters, e.g., single particle model (SPM) [16], single particle model with electrolyte dynamics (SPMe) [17], and electrode average model [18]. Other KF variants were also studied, including robust EKF (REKF) [19], adaptive EKF (AEKF) [20], and adaptive UKF (AUKF) [21]. Besides KFs, smooth variable structure filter (SVSF) [22], sliding-mode observer (SMO) [23], backstepping PDE observer [24], nonlinear geometric observer [25], and Luenberger-type observers [26] were applied as well. Based on a reduced electrochemical model, the optimization-based moving horizon estimation (MHE) framework has been systematically assessed for advanced battery condition monitoring [27]. MHE and mMHE are more precise than EKF/UKF; however, it has slower computation.

In this work, a new balancing strategy called hybrid natural and forced active balancing control (HNFABC) is put forward, the operating principle of which is mainly based on the energy transmission of unbalanced current flowing from overcharged batteries to overdischarged batteries. In this case, energy naturally flows to a low-energy battery without any measurement sensor equipment. Additionally, there is no need to use a sensor to measure the voltage of batteries by utilizing the proposed scheme. Forced balancing works by precisely controlling the drive switch to transfer energy from inconsistent battery packs to all other battery packs. The proposed natural equalization control can achieve active equalization by utilizing the energy difference of the battery itself without external forced control. Forced equalization can solve the problem of slow equilibrium in the final stage of natural equilibrium, but the battery will be repeatedly charged and discharged. The finally proposed hybrid natural forced equalization control can combine the advantages of the two kinds of control above and realize the rapid equalization while the battery is only in a state of charging or discharging. In this paper, the HNFABC means that energy is naturally transferred from overcharged cells to overdischarged cells with forced energy transfer donors and acceptors during equilibrium process. To further verify the feasibility of the proposed strategy, the equalization circuit simulation system is built in PSIM. Whilst an unscented Kalman filter is used in a Matlab/Simulink model of battery packs based on the partnership of a new generation of vehicles (PNGV). Finally, experiments are provided to verify the effectiveness and superiority of the proposed technology.

This paper is organized in the following ways. The design and operational principle of the complementary equalization topology and its control algorithm are explained in Section 2. Simulation and experimental results are presented in Section 3. The conclusions and key research content for future work are provided in Section 4.

\section{Operating Principle and Design}

Replacing the diodes in the traditional buck-boost circuit with MOSFET transistors enables bidirectional power transfer and continuous current mode [28-32]. The system flow of the equalization technology is shown in Figure 1. This improved buck-boost circuit can transfer energy from batteries to any other batteries. Each equalization module is connected inductively between two battery packs. The structure consists of $n$ cells in series, which is applicable to the battery pack equalization circuit, is as shown in Figure 2 . The access of the equalization module divides the battery components into upper and lower parts, which can transfer energy in the upper and lower parts, thereby achieving equalization of the battery pack. The circuit topology proposed in this paper can also individually adjust the energy of any battery to be transferred to the rest of other batteries in the battery pack. Compared with the traditional equalization circuit, this topology can flexibly realize battery energy balance and is easy to expand. Each equalization circuit divides the battery components into two parts, whose energy can be primarily transferred to each other. Furthermore, combining two equalization circuits enables any single battery energy to be transferred to the remaining batteries in the battery pack by controlling the two switching tubes.

2.1. Natural Active Balancing Control. The transistors in each equalizer block in the circuit operate in a complementary drive mode with a duty cycle a set as a function of input voltage and output voltage:

$$
\begin{aligned}
\alpha_{i} & =\frac{U_{\mathrm{Hi}}}{\left(U_{\mathrm{Li}}+U_{\mathrm{Hi}}\right)}, \\
\alpha_{i} U_{\mathrm{Li}}-R_{\mathrm{INeq}} \alpha_{i} I_{\mathrm{Lm}} & =\left(1-\alpha_{i}\right) U_{\mathrm{Hi}}+R_{\mathrm{OUTeq}}\left(1-\alpha_{i}\right) I_{\mathrm{Lm}}, \\
I_{\mathrm{Lm}} & =\frac{\alpha_{i} U_{\mathrm{Li}}-\left(1-\alpha_{i}\right) U_{\mathrm{Hi}}}{R_{\mathrm{INeq}} \alpha_{i}+R_{\mathrm{OUTeq}}\left(1-\alpha_{i}\right)},
\end{aligned}
$$

where subscript $i$ is the number of cells on the input leg, $i \in$ int $[1 ; N-1], U_{\mathrm{Hi}}$ is the input cell voltage, $U_{\mathrm{Li}}$ is the output cell voltage, $R_{\mathrm{INeq}}$ stands for the equivalent resistance of the input circuit, $R_{\text {OUTeq }}$ stands for the equivalent resistance of the output circuit, and $I_{\mathrm{Lm}}$ means the balancing current that natural energy transfer from any overcharged cells to any undercharged cells is possible which are produced by any unbalanced voltage across each converter inductor leg. This fixed duty cycle equalization mode produces an average voltage on one side of the inductor that is 


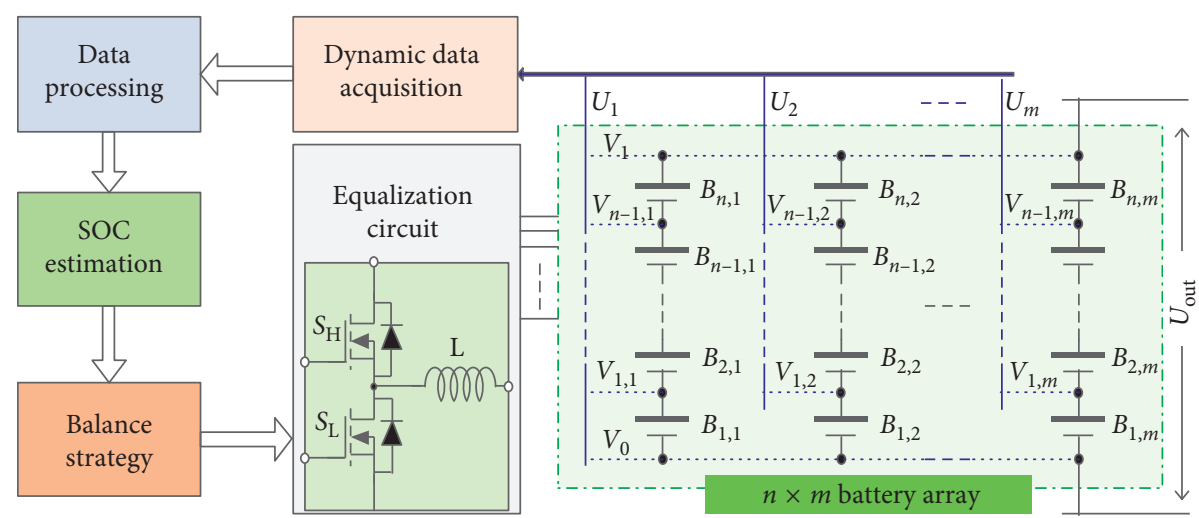

FIGURE 1: Equalization system block diagram.

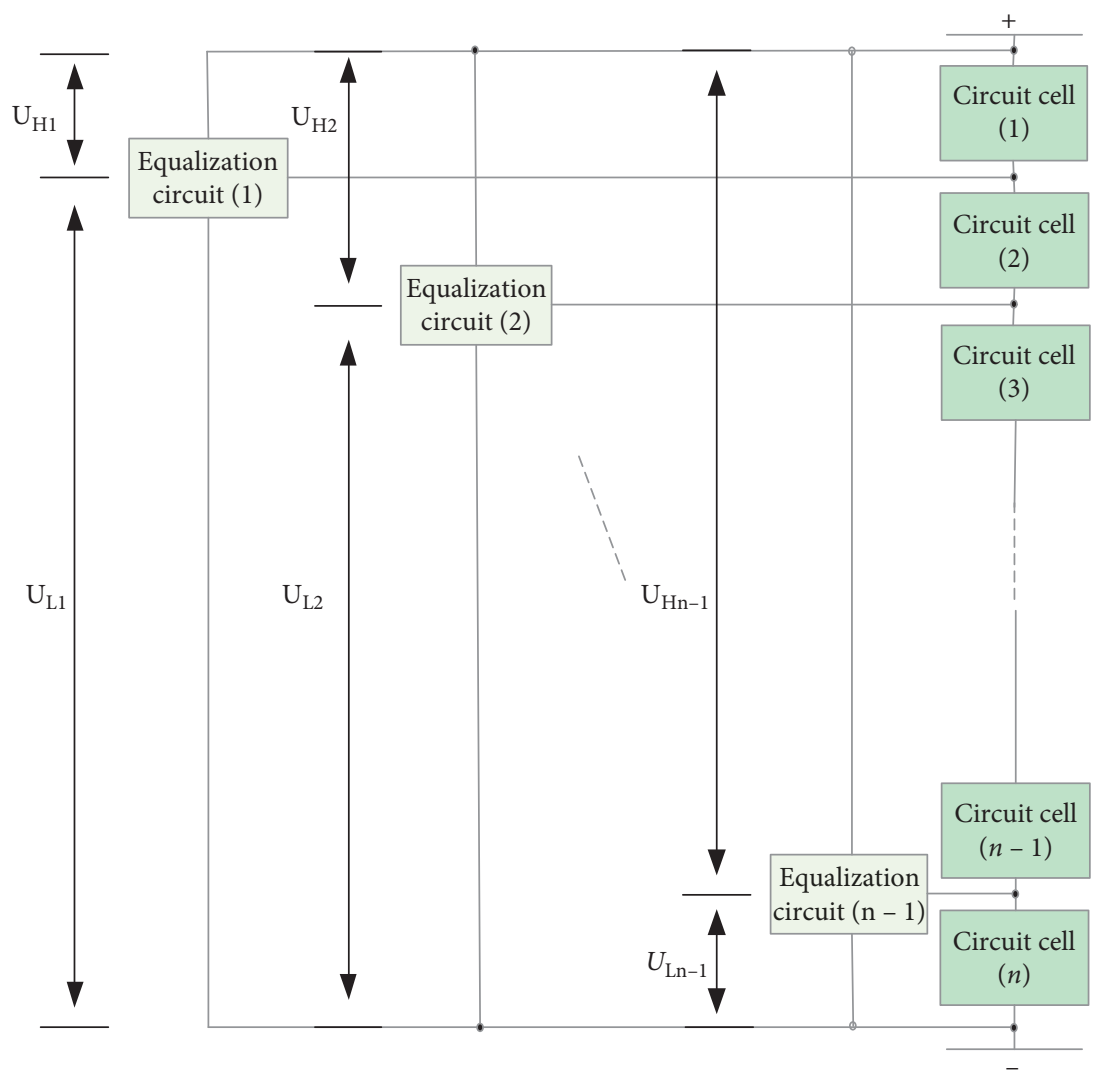

FIGURE 2: Equalization control circuit topology.

equal to a portion of the battery pack voltage. If the energy of the two cells separated by the inductance is balanced, the potential generated at both ends of the inductor is the same; that is, the energy absorbed by the inductor from a part of the circuit is equal to the energy released from the other part of the circuit. If the energy of the two parts of the battery pack is not balanced, the inductor will transfer the energy of the battery pack whose energy is higher than the set value to the battery pack below the set value. The duty ratio of the switching tubes in each equalization module in the equalization circuit is given in Table 1. Further, under natural active balancing control strategy, these switches are operated in a complementary mode.
TABLE 1: Duty cycle rate of equalization circuit.

\begin{tabular}{lcccccc}
\hline \multirow{2}{*}{ Switch } & \multicolumn{5}{c}{ Duty cycle } \\
& $\mathrm{EC}(1)$ & $\mathrm{EC}(2)$ & $\ldots$ & $\mathrm{EC}(i)$ & $\ldots$ & $\mathrm{EC}(n-1)$ \\
\hline$S_{\mathrm{H}}$ & $n-1$ & $n-2$ & $\ldots$ & $n-i$ & $\ldots$ & 1 \\
$S_{\mathrm{L}}$ & 1 & 2 & $\ldots$ & $i$ & $\ldots$ & $n-1$ \\
\hline
\end{tabular}

2.2. Forced Active Balancing Control. To reduce the energy circulation caused by natural active balancing control, a novel forced active equalization control is proposed. Current flow direction is indicated by the red arrow. As shown in Figure 3, the topology can easily achieve the balance control of the front battery and the rear battery: turn on the switch 

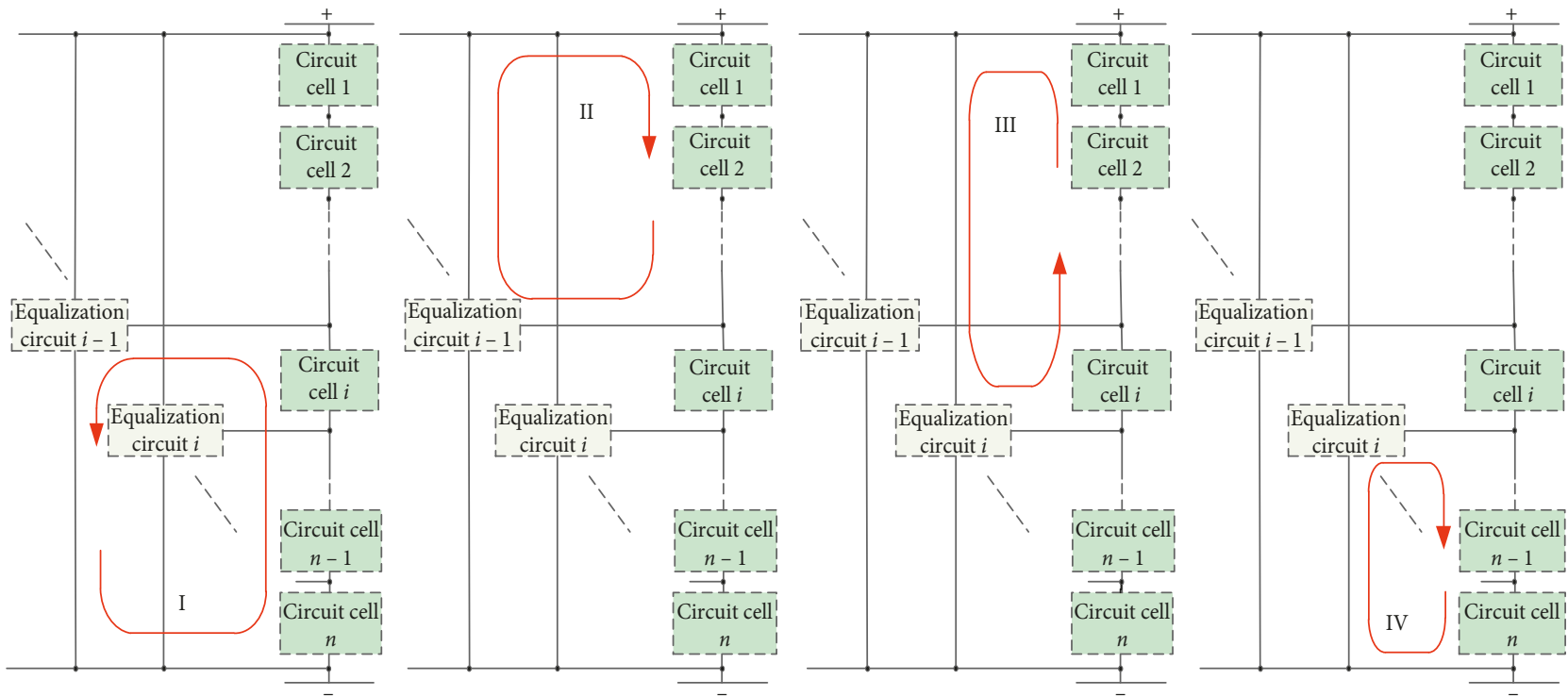

Figure 3: Energy transfer path schematic. (a) Mode I, (b) mode II, (c) mode III, and (d) mode IV.

$S_{\mathrm{Li}-1}$, the current flow is shown in mode I; then, turn off the switch $S_{\mathrm{Li}-1}$, the current flow is shown in mode II. Further, if the energy of an overcharged battery in the series battery pack is transferred to all other batteries, the above steps need to be performed, and the switch $S_{\mathrm{Hi}}$ needs to be controlled to turn on. The current flow is as shown in mode III; then, the switch $S_{\mathrm{Hi}}$ is turned off, current flow is shown in mode IV. The status of each switch from mode I to mode IV is shown in Table 2.

\subsection{Hybrid Naturally and Forced Active Balancing Control.} Further, the series equilibrium of $N$ batteries is mathematically verified. The principle is as follows: supposing that the energy of $B_{i}$ is more than the average value of other batteries, it should be transferred to the other batteries. The inductor absorbs energy given out from each battery between $B_{i}$ and $B_{n}$ is $\Delta \varepsilon_{1}$ under mode I. The inductor releases energy to the rest batteries from $B_{1}$ to $B_{i-1}$ under mode II. The inductor that absorbs energy given out from each battery between $B_{1}$ and $B_{i}$ is $\Delta \varepsilon_{2}$ under mode III. The inductor releases energy to the rest batteries from $B_{i+1}$ to $B_{n}$ under mode IV. The difference between the energy of the battery $B_{i}$ and the average energy of the battery pack is defined as $Q_{i}^{\text {extra }}$. For the amount of energy that is transferred from the single cell in the battery pack, formula (4) and formula (5) are listed:

$$
\begin{gathered}
\frac{(n-i+1) \Delta \varepsilon_{1}}{(i-1)-\Delta \varepsilon_{2}}=\frac{Q_{i}^{\text {extra }}}{n}, \\
\frac{-\Delta \varepsilon_{1}+i \Delta \varepsilon_{2}}{(n-i)}=\frac{Q_{i}^{\text {extra }}}{n} .
\end{gathered}
$$

The simultaneous equations are solved as follows:
TABLE 2: Switching state during equalization.

\begin{tabular}{lcccc}
\hline Switch & Mode I & Mode II & Mode III & Mode IV \\
\hline$S_{\mathrm{H}(i-1)}$ & Off & Off & Off & Off \\
$S_{\mathrm{L}(i-1)}$ & On & Off & Off & Off \\
$S_{\mathrm{H}(i)}$ & Off & Off & On & Off \\
$S_{\mathrm{L}(i)}$ & Off & Off & Off & Off \\
\hline
\end{tabular}

$$
\begin{aligned}
& \Delta \varepsilon_{1}=\frac{(i-1) Q_{i}^{\text {extra }}}{n}, \\
& \Delta \varepsilon_{2}=\frac{(n-i) Q_{i}^{\text {extra }}}{n} .
\end{aligned}
$$

This process can be realized only by controlling two switch tubes. The circuit simplifies the design, facilitates the controlling strategy and is easy to expand for different numbers of series battery packs. Because the structure of the $\mathrm{N}$-phase circuit is completely the same, the difference is that the inductor is connected to the battery pack at one end, so the circuit will be further simplified as shown in Figure 4.

\section{Battery Model and Equilibrium Simulation}

3.1. Battery Parameters Module. PNGV model is shown in Figure 5 [33-35]. Compared with the Thevenin model and $R_{\text {int }}$ model, this PNGV model has higher precision and describes the transient response process of the battery better. In the model, $U_{\mathrm{OC}}$ is the ideal voltage source and represents the open-circuit voltage of the battery; $R_{0}$ is the internal resistance of the battery; $R_{\mathrm{P}}$ is the polarization resistance; $C_{\mathrm{P}}$ is the polarization capacitance; $I_{\mathrm{P}}$ is the current floated on the polarization resistance; when describing the load current, $C_{B}$ is the capacitance that describes the changing voltage, which, accumulates in the open circuit.

Available for circuit diagrams for $C_{\mathrm{B}}$ and $C_{\mathrm{P}}$ : 

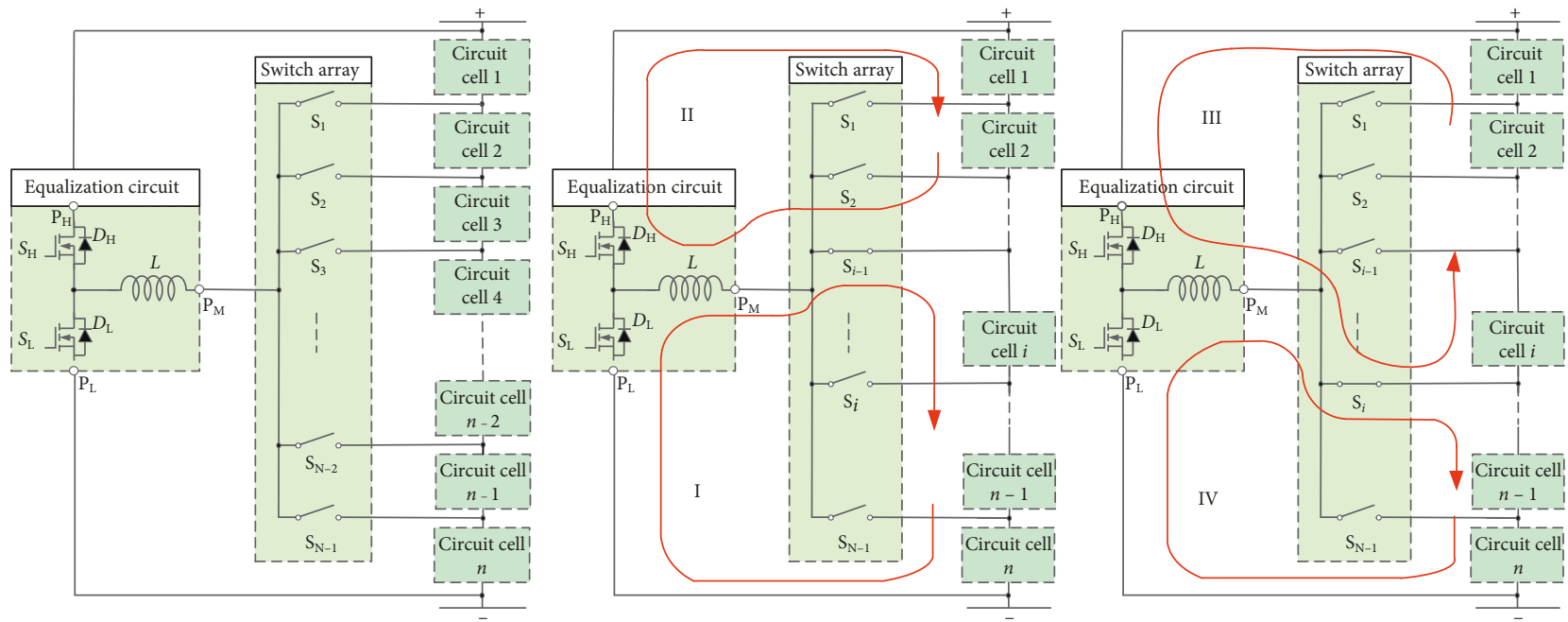

FIGURE 4: Simplified equalization circuit and its working principle. (a) Simplified equalization circuit, (b) when switch $S_{i-1}$ is closed, and (c) when switch $S_{i}$ is closed.

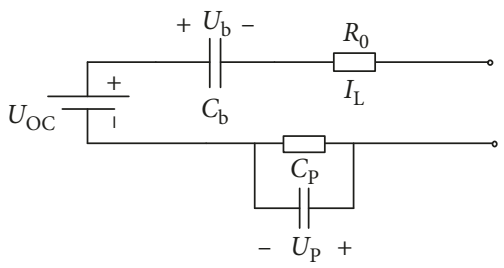

FIgURE 5: PNGV equivalent circuit model.

$$
\begin{aligned}
C_{\mathrm{b}} \frac{d U_{\mathrm{b}}}{d t} & =I_{\mathrm{L}}, \\
C_{\mathrm{p}} \frac{d U_{\mathrm{P}}}{d t} & =I_{\mathrm{L}}-\frac{U_{\mathrm{P}}}{R_{\mathrm{P}}} .
\end{aligned}
$$

According to Kirchhoff's voltage law, the open circuit voltage $U_{\text {OC }}$ can be as follows:

$$
U_{\mathrm{OC}}=U_{\mathrm{b}}+U_{\mathrm{P}}+I_{\mathrm{L}} R_{0}+U_{\mathrm{L}}
$$

The state equation for establishing the PNGV model with the two capacitor voltages $U_{\mathrm{B}}$ and $U_{\mathrm{P}}$ in the model is

$$
\left\{\begin{array}{l}
{\left[\begin{array}{c}
U_{\mathrm{b}} \\
U_{\mathrm{P}}
\end{array}\right]=\left(\begin{array}{c}
0 \\
0 \\
0-\frac{1}{C_{\mathrm{P}} R_{\mathrm{P}}}
\end{array}\right)=\left[\begin{array}{c}
U_{\mathrm{b}} \\
U_{\mathrm{P}}
\end{array}\right]\left[\begin{array}{c}
\frac{1}{C_{b}} \\
\frac{1}{C_{\mathrm{P}}}
\end{array}\right]\left[I_{\mathrm{L}}\right],} \\
U L=[-1,-1]\left[\begin{array}{c}
U_{\mathrm{b}} \\
U_{P}
\end{array}\right]+\left[-R_{0}\right]\left[I_{\mathrm{L}}\right]+\left[U_{\mathrm{OC}}\right] .
\end{array}\right.
$$

The state equation uses the two capacitor voltages of the PNGV model as the state variables and the battery terminal voltage as the output variable. The SOC is not a measure that can be measured specifically. The electrical quantity that can be measured in the model is only the port voltage $U_{\mathrm{OC}}$ and the port current $I_{\mathrm{L}}$. Therefore, the existing measurement value must be used to select an appropriate SOC estimation method.
3.2. The Analysis of the Simulation Results. The natural equalization control strategy and HNFABC strategy of the circuits above are verified, respectively. In this section, a software simulation, including a PNGV model and an experimental system that contains four cells of lithium-ion batteries, is built.

In the experiment, the energy of the $B_{2}$ was set higher than other batteries in the battery pack $\left(U_{\mathrm{B} 2}=4 \mathrm{~V}, U_{\mathrm{B} 1}, U_{\mathrm{B} 3}\right.$, and $U_{\mathrm{B} 4}=3.6 \mathrm{~V}, i=2$ ). Specifically, the process of transferring the excess energy of the $B_{2}$ to other batteries was simulated and verified. For the equalization circuit that consisted of four batteries, the equalization process will undergo four modes as shown in Figure 3. VP1 to VP4 stand for the voltage of each battery. The equalization circuit composed of two batteries will be equipped with an equalization module. The equalization circuit composed of three batteries will be equipped with two equalization modules. The equalization circuit composed of $n$ batteries has an equalization module number of $n-1$. The simulation experiments of the four-cell battery are built under the natural equalization and $\mathrm{HNFABC}$ strategy, respectively. The dynamic voltage waveform is shown in Figures 6 and 7.

Figure 8 is the inductor current of the EC1 equalization module and the EC2 equalization module. The function of the equalization module EC1 is to achieve the balance between the $B_{1}$ and the battery 234. The function of the equalization module EC2 is to achieve the balance between the battery and the $\mathrm{B}_{3}$ or $\mathrm{B}_{4}$. As is shown in Figure $6(\mathrm{a})$, when the equalization circuit operates, the switch $S_{\mathrm{L} 1}$ is turned on first, transferring the energy of $\mathrm{B}_{2}, \mathrm{~B}_{3}$, and $\mathrm{B}_{4}$ to inductor $L_{1}$, and the inductor $L_{1}$ transfers energy to $B_{1}$. As is shown in Figure 6(b), when the equalization circuit is working, the switch $S_{\mathrm{H} 2}$ is turned on first, transferring the energy of the $\mathrm{B}_{1}$ and $\mathrm{B}_{2}$ to the inductor $L_{2}$, and then, the inductor $L_{2}$ transfers the energy to $B_{3}$ and $B_{4}$.

3.3. The Analysis of the Experiment Results. The experimental platform was built in the laboratory as shown in Figure 9. 


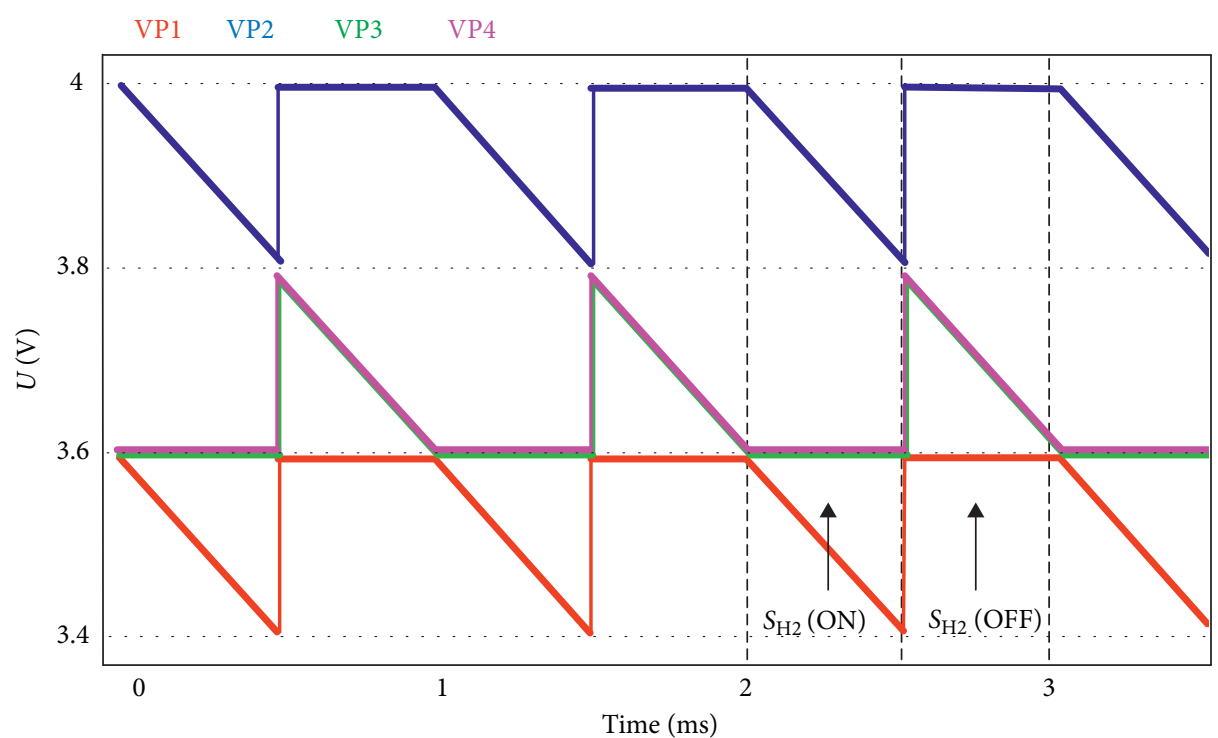

(a)

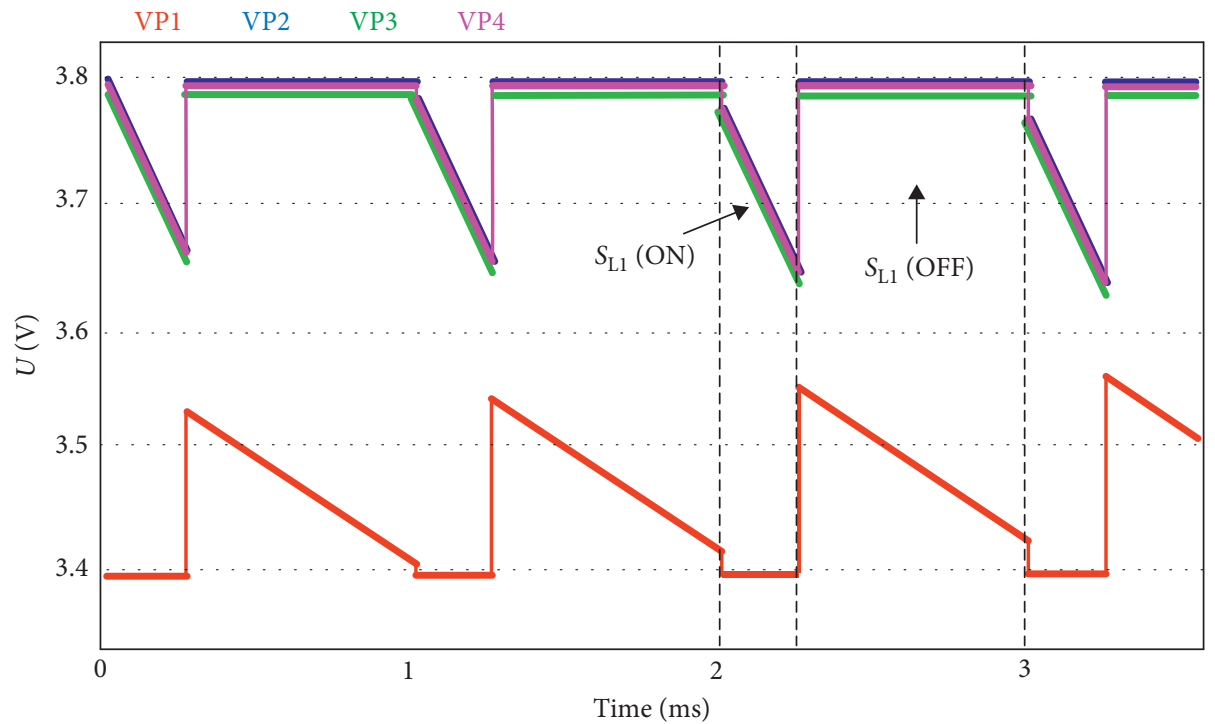

(b)

FIGURE 6: Waveforms for four battery cells energy equalization. (a) Battery voltage in mode I and mode II and (b) battery voltage in mode III and mode IV.

Simulation and experimental verifications have been completed, respectively. The system parameters of the experiment are shown in Table 3.

For simulating and comparing the battery balance in the idle state $\left(B_{\mathrm{H}}>B_{\mathrm{L}}\right)$, Figure 10 (a) shows the simulation results in a dynamic equalization process and Figure 10(b) shows the experiment results. Basically, it can be seen from the figure that the experimental waveform and the simulation results are consistent with the theoretical design.

3.4. Analysis of the Results. The feasibility of the equalization circuit and its control strategy described in this paper is verified, after comparing the simulation with experiment results. Based on the above four-cell experimental circuit, the same parameters were used for simulation. Taking a battery equalization unit as an example, to compare its dynamic balance effect, Figure 8 shows the working waveforms when the same battery operates in idle states, including switch status and current, where Figure 8 is the actual results of the simulation and experiments, respectively. The waveforms of transforming current in experimental results are basically consistent with which in the simulation process, through comparison and observation.

Further, during the equalization process, the equalization voltage of the four-cell battery, under traditional control and HNFABC, is drawn into a line graph as Figure 11 shows. In the experiment, the battery voltage was measured once a minute and was more intuitively plotted with line graphs. Compared with the traditional control strategy, it is obvious that the HNFABC strategy can achieve a faster balance. 


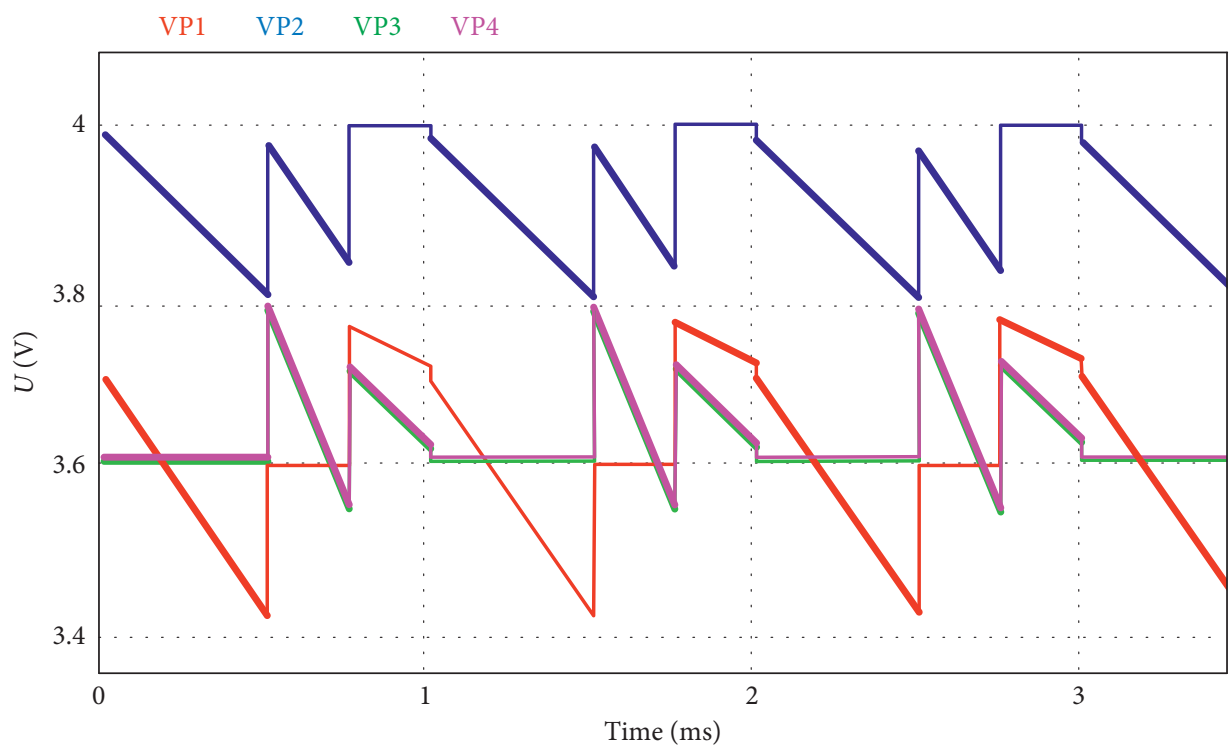

Figure 7: Battery pack voltage under HNFABC.

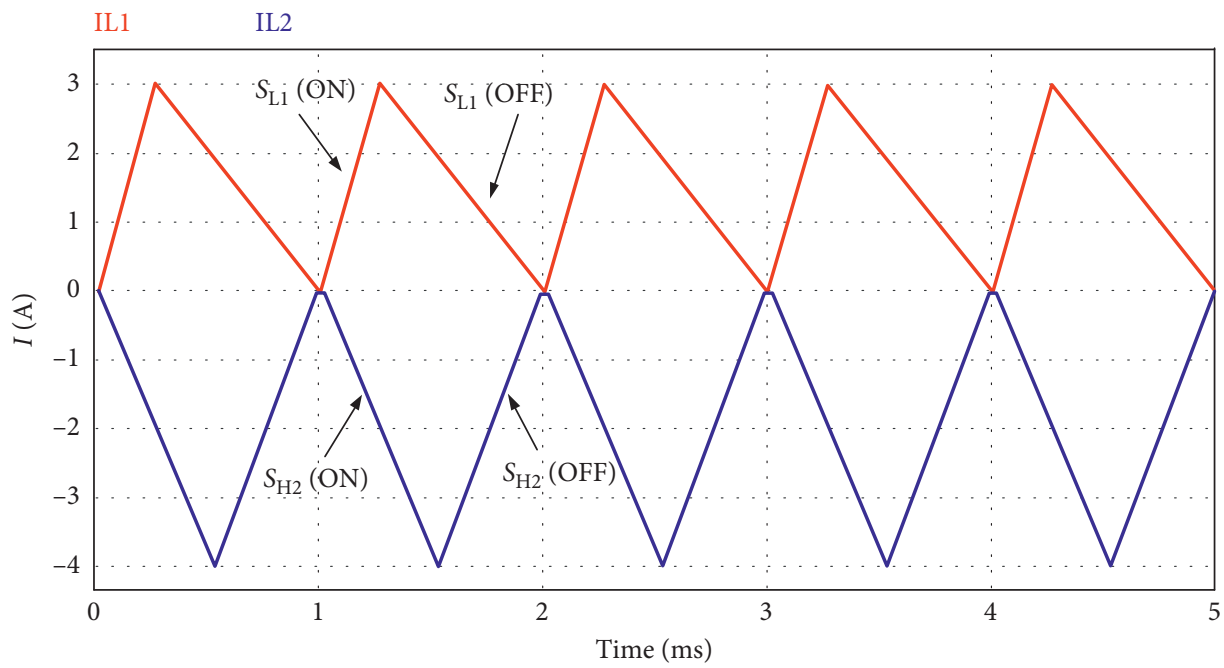

Figure 8: Current flow on inductor in HNFABC.

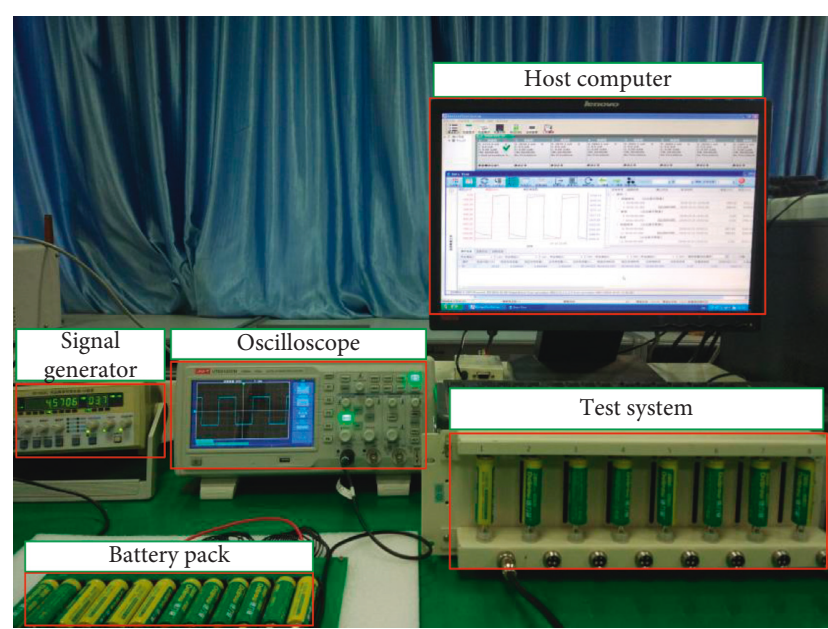

FIGURE 9: Experiment platform of the equalization circuit.
TABLE 3: Simulation and experimental specifications.

\begin{tabular}{lc}
\hline Item & Description \\
\hline Control chip & STM32F103 \\
Battery parameter & $4.2 \mathrm{~V}, 1 \mathrm{AH}$ \\
Inductance value & $100 \mu \mathrm{H}$ \\
Switch model & IRF530 \\
Operating frequency & $10 \mathrm{kHz}$ \\
Duty cycle of $S_{\mathrm{H} 2}$ & $50.0 \%$ \\
Duty cycle of $S_{\mathrm{L} 1}$ & $33.3 \%$ \\
Initial state of $\mathrm{B}_{1}$ & $3.6 \mathrm{~V}$ \\
Initial state of $\mathrm{B}_{2}$ & $4.0 \mathrm{~V}$ \\
Initial state of $\mathrm{B}_{3}$ & $3.6 \mathrm{~V}$ \\
Initial state of $\mathrm{B}_{4}$ & $3.6 \mathrm{~V}$ \\
\hline
\end{tabular}

In the experiment, the energy of one battery is higher than that of other battery cells. The distinctive of HNFABC strategy will be more obvious than the traditional strategy, 


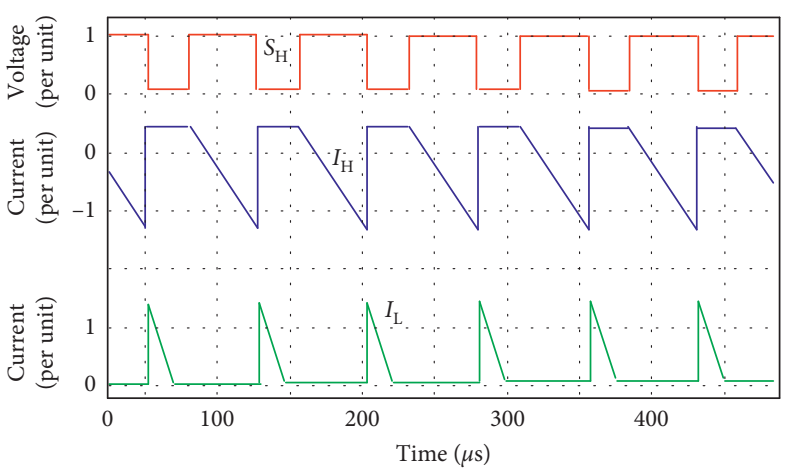

(a)

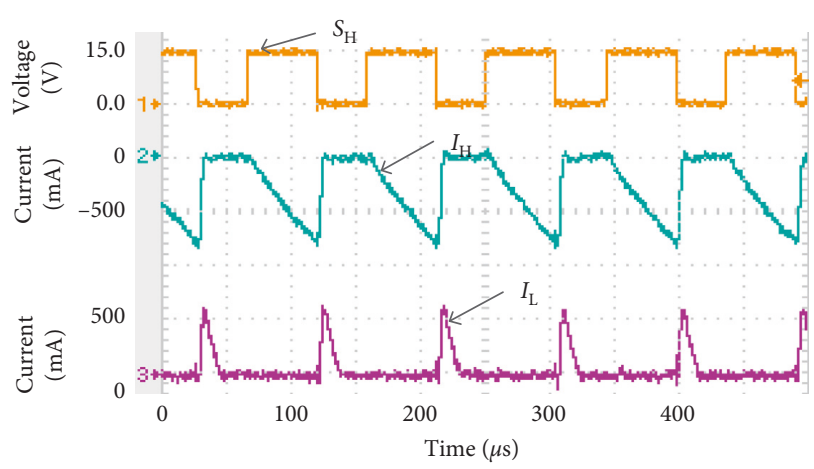

(b)

FIGURE 10: The dynamic characteristics of the battery equalization process: (a) simulation and (b) experiment.

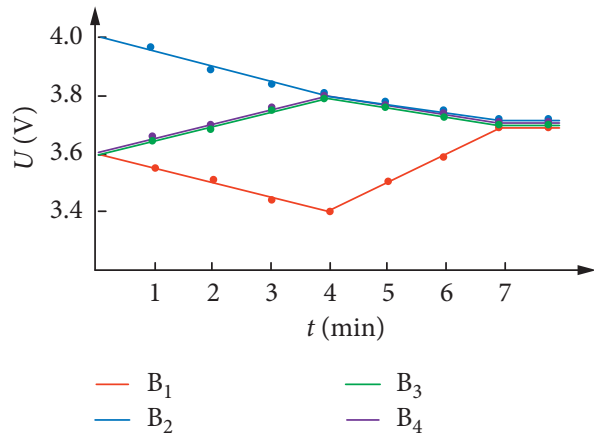

(a)

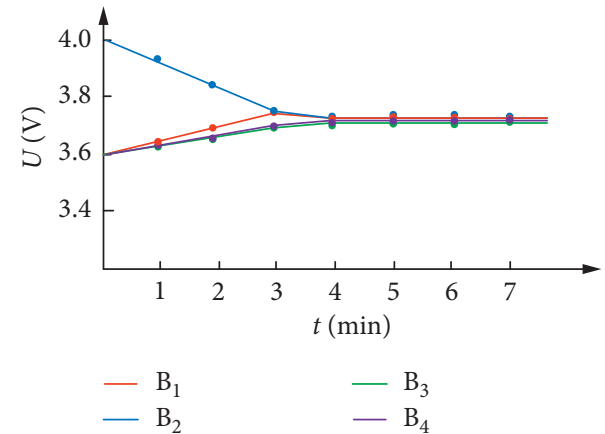

(b)

FIGURE 11: Equalization time for experiments: (a) traditional control and (b) HNFABC.

however, considering the battery's power distribution is rather complicated in actual circumstances.

The characteristics of the equalization circuit are characterized by loss, time, complexity, and extended battery life. After a comprehensive comparison of the above three equalization methods, the overall advantage of the HNFABC strategy is obvious. As is shown in Figure 12, especially in terms of loss, the energy loss is reduced by more than $50 \%$ compared to the resistance dissipation equalization method.

\section{Conclusions}

This paper proposed the concept of HNFABC strategy for a fast-balancing battery cells system based on the PNGV model. The experimental results have demonstrated that the complementary equalization circuit topology with the HNFABC strategy achieves battery balancing, prolongs the life of the battery pack, and reduces the energy loss in the balancing progress. The main advantage of this structure is that, in order to transfer the energy that belongs to one battery to all others, only two switches are needed to control. The simulation results also proved that compared to traditional balancing control, the new strategy effectively utilizes switches to change and implement the controlling effect. The waveform and experiment results have indicated that the proposed control strategy is effective and feasible. In practical applications, the number of batteries with

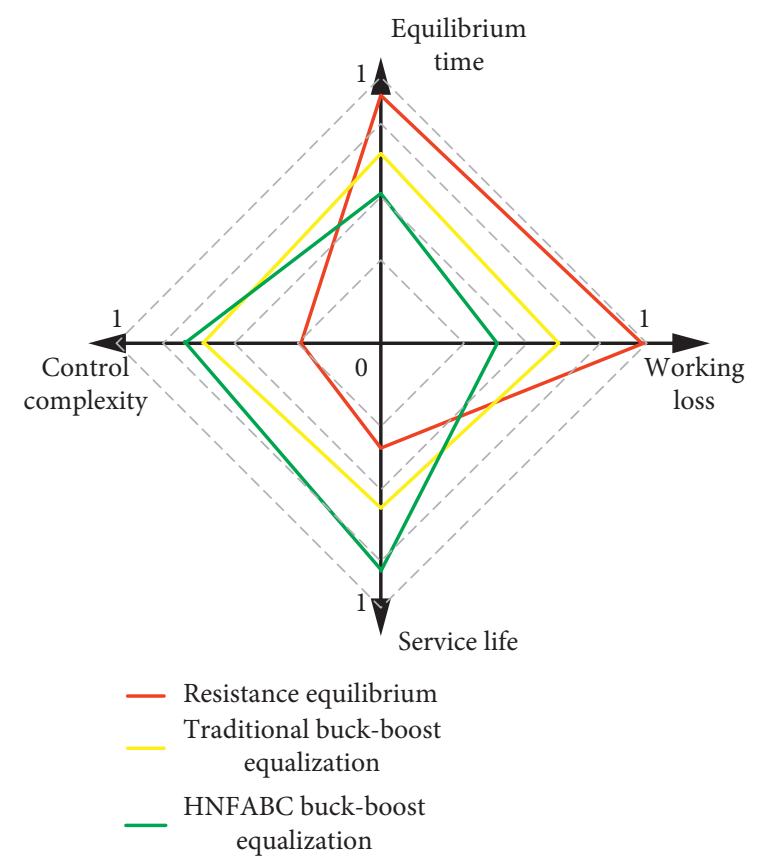

FIGURE 12: Multidimensional comparison equalization strategy (p.u.).

abnormal energy in the battery pack is arbitrary. This design only transfers the energy of one abnormal battery to the remaining batteries in the battery pack. Future research will 
be more focused on the actual circumstances, to design and to propose a multicell abnormal energy balance control method that is more suitable for engineering practice.

\section{Data Availability}

The data used to support the findings of this study are available from the corresponding author upon request.

\section{Conflicts of Interest}

The authors declare that they have no conflicts of interest.

\section{Authors' Contributions}

Shuailong Dai proposed a novel battery pack equalization system, aiming to achieve the balancing process under hybrid natural and forced active balancing control and set up the experimental platform and conducted the experiments. Jiayu Wang and Zhifei Shan designed and implemented the balancing circuit. Jie Min drafted the manuscript. Yewen Wei finalized and polished the manuscript.

\section{Acknowledgments}

This research work was supported by the Excellent Young and Middle-aged Science and Technology Innovation Team of Hubei Education Department T201504 and National Innovation and Entrepreneurship Training Program for College Students 201711075009.

\section{References}

[1] K. Yang and A. Walid, "Outage-storage tradeoff in frequency regulation for smart grid with renewables," IEEE Transactions on Smart Grid, vol. 4, no. 1, pp. 245-252, 2013.

[2] T. Masuta and A. Yokoyama, "Supplementary load frequency control by use of a number of both electric vehicles and heat pump water heaters," IEEE Transactions on Smart Grid, vol. 3, no. 3, pp. 1253-1262, 2012.

[3] J. Escudero-Garzas, A. Garcia-Armada, and G. Seco-Granados, "Fair design of plug-in electric vehicles aggregator for V2G regulation," IEEE Transactions on Vehicular Technology, vol. 61, no. 8, pp. 3406-3419, 2012.

[4] A. Khaligh and Z. Li, "Battery ultracapacitor fuel cell and hybrid energy storage systems for electric hybrid electric fuel cell and plug-in hybrid electric vehicles: state of the art," IEEE Transactions on Vehicular Technology, vol. 59, no. 6, pp. 2806-2814, 2010.

[5] J. C. Gómez and M. M. Morcos, "Impact of EV battery chargers on the power quality of distribution systems," IEEE Transactions on Power Delivery, vol. 18, no. 3, pp. 975-981, 2003.

[6] S. Han, S. Han, and K. Sezaki, "Development of an optimal vehicle-to-grid aggregator for frequency regulation," IEEE Transactions on Smart Grid, vol. 1, no. 1, pp. 65-72, 2010.

[7] E. Inoa and J. Wang, "PHEV charging strategies for maximized energy saving," IEEE Transactions on Vehicular Technology, vol. 60, no. 7, pp. 2978-2986, 2011.

[8] L. Ni, D. J. Patterson, and J. L. Hudgins, "High power current sensorless bidirectional 16-phase interleaved DC-DC converter for hybrid vehicle application," IEEE Transactions on Power Electronics, vol. 27, no. 3, pp. 1141-1151, 2012.

[9] S. W. Lee, K. M. Lee, Y. G. Choi, and B. Kang, "Modularized design of active charge equalizer for Li-ion battery pack," IEEE Transactions on Industrial Electronics, vol. 65, no. 11, pp. 8697-8706, 2018.

[10] A. M. Imtiaz and F. H. Khan, "Time shared a flyback converter based regenerative cell balancing technique for series connected Li-Ion battery strings," IEEE Transaction on Power Electronics, vol. 28, no. 12, pp. 5960-5975, 2013.

[11] C. S. Lim, K. J. Lee, N. J. Ku, D. S. Hyun, and R. Y. Kim, “A modularized equalization method based on magnetizing energy for a series-connected lithium-ion battery string," IEEE Transactions on Power Electronics, vol. 29, no. 4, pp. 1791-1799, 2014.

[12] W. Huang and J. A. A. Qahouq, "Energy sharing control scheme for state-of-charge balancing of distributed battery energy storage system," IEEE Transactions on Industrial Electronics, vol. 62, no. 5, pp. 2764-2776, 2015.

[13] Y. Wei, Y. Li, B. Cao, B. Zhu, and G. Liu, "Research on power equalization of lithium-ion batteries with less-loss buck chopper," Transactions of China Electrotechnical Society, vol. 33, no. 11, pp. 2575-2583, 2018.

[14] G. L. Plett, "Extended kalman filtering for battery management systems of LiPB-based hev battery packs: part 3. state and parameter estimation," Journal of Power Sources, vol. 134, no. 2, pp. 277-292, 2004.

[15] G. L. Plett, "Sigma-point kalman filtering for battery management systems of LiPB-based hev battery packs: Part 2: simultaneous state and parameter estimation," Journal of Power Sources, vol. 161, no. 2, pp. 1369-1384, 2006.

[16] S. Santhanagopalan and R. E. White, "Online estimation of the state of charge of a lithium ion cell," Journal of Power Sources, vol. 161, no. 2, pp. 1346-1355, 2006.

[17] S. Santhanagopalan and R. E. White, "State of charge estimation using an unscented filter for high power lithium ion cells," International Journal of Energy Research, vol. 34, no. 2, pp. 152-163, 2010.

[18] D. D. Domenico, A. Stefanopoulou, and G. Fiengo, "Lithiumion battery state of charge and critical surface charge estimation using an electrochemical model-based extended kalman filter," Journal of Dynamic Systems, Measurement, and Control, vol. 132, no. 6, article 061302, 2010.

[19] X. Hu, F. Sun, and Y. Zou, "Comparison between two modelbased algorithms for li-ion battery soc estimation in electric vehicles," Simulation Modelling Practice and Theory, vol. 34, pp. 1-11, 2013.

[20] J. Han, D. Kim, and M. Sunwoo, "State-of-charge estimation of lead-acid batteries using an adaptive extended kalman filter," Journal of Power Sources, vol. 188, no. 2, pp. 606-612, 2009.

[21] F. Sun, X. Hu, Y. Zou, and S. Li, "Adaptive unscented kalman filtering for state of charge estimation of a lithium-ion battery for electric vehicles," Energy, vol. 36, no. 5, pp. 3531-3540, 2011.

[22] T. Kim, Y. Wang, H. Fang et al., "Model-based condition monitoring for lithium-ion batteries," Journal of Power Sources, vol. 295, pp. 16-27, 2015.

[23] I.-S. Kim, "Nonlinear state of charge estimator for hybrid electric vehicle battery," IEEE Transactions on Power Electronics, vol. 23, no. 4, pp. 2027-2034, 2008.

[24] S. Moura, N. Chaturvedi, and M. Krstic, "PDE estimation techniques for advanced battery management systems-part i: SOC estimation," in Proceedings of American Control Conference (ACC), 2012, pp. 559-565, Montreal, Canada, June 2012. 
[25] Y. Wang, H. Fang, Z. Sahinoglu, T. Wada, and S. Hara, "Adaptive estimation of the state of charge for lithium-ion batteries: nonlinear geometric observer approach," IEEE Transactions on Control Systems Technology, vol. 23, no. 3, pp. 948-962, 2015.

[26] S. Dey, B. Ayalew, and P. Pisu, "Nonlinear robust observers for state-of charge estimation of lithium-ion cells based on a reduced electrochemical model," IEEE Transactions on Control Systems Technology, vol. 23, no. 5, pp. 1935-1942, 2015.

[27] X. Hu, D. Cao, and E. Bo, "Condition monitoring in advanced battery management systems: moving horizon estimation using a reduced electrochemical model," IEEE/ASME Transactions on Mechatronics, vol. 23, no. 1, pp. 167-178, 2018.

[28] S. Dai, W. Yewen, X. Zhang et al., "Low-loss power equalization technique for Li-ion battery," Battery Bimonthly, vol. 48, no. 3, pp. 175-178, 2018.

[29] J. Li and J. Jiang, "Active capacitor voltage balancing methods based on dynamic model for five-level nested neutral point piloted converter," IEEE Transactions on Power Electronics, vol. 33, no. 8, pp. 6567-6581, 2018.

[30] D. Yang, N. Wu, L. Yin, and Z. Lu, "Natural frame control of single-phase cascaded $\mathrm{H}$-bridge multilevel converter based on fictive-phases construction," IEEE Transactions on Industrial Electronics, vol. 65, no. 5, pp. 3848-3857, 2017.

[31] F. Mestrallet, L. Kerachev, J. C. Crebier, and A. Collet, "Multiphase interleaved converter for lithium battery active balancing," IEEE Transactions on Power Electronics, vol. 29, no. 6, pp. 2874-2881, 2014.

[32] V. Yuhimenko, G. Geula, G. Agranovich, M. Averbukh, and A. Kuperman, "Average modeling and performance analysis of voltage sensorless active supercapacitor balancer with peak current protection," IEEE Transactions on Power Electronics, vol. 32, no. 2, pp. 1570-1578, 2016.

[33] C. Liu, W. Liu, L. Wang, G. Hu, L. Ma, and B. Ren, “A new method of modeling and state of charge estimation of the battery," Journal of Power Sources, vol. 320, pp. 1-12, 2016.

[34] X. Liu, W. Li, and A. Zhou, "PNGV equivalent circuit model and SOC estimation algorithm for lithium battery pack adopted in AGV vehicle," IEEE Access, vol. 6, pp. 2363923647, 2018.

[35] X. Hu, R. Xiong, and B. Egardt, "Model-based dynamic power assessment of lithium-ion batteries considering different operating conditions," IEEE Transactions on Industrial Informatics, vol. 10, no. 3, pp. 1948-1959, 2014. 


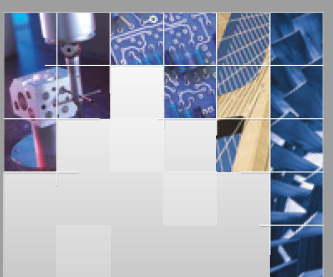

\section{Enfincering}
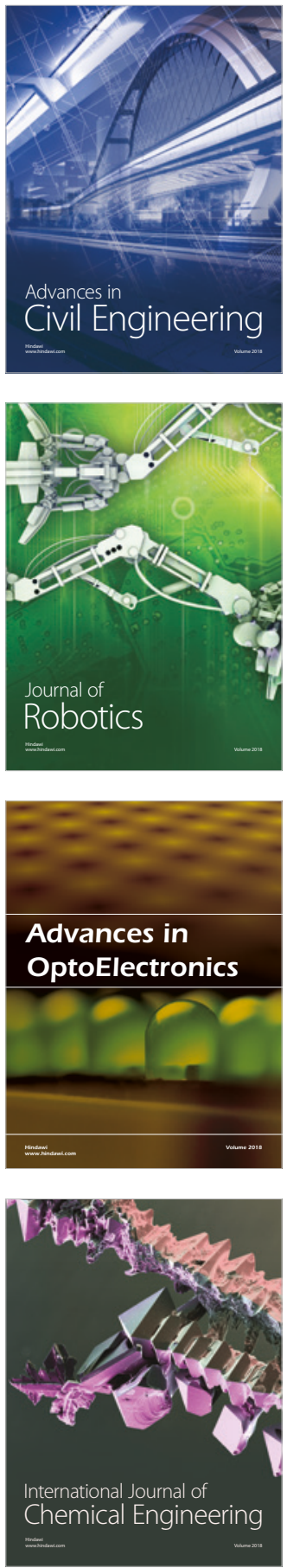

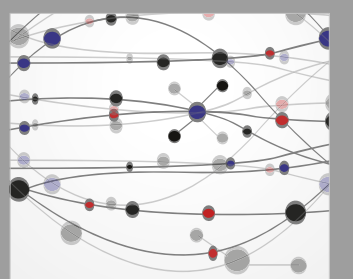

\section{Rotating \\ Machinery}

The Scientific World Journal

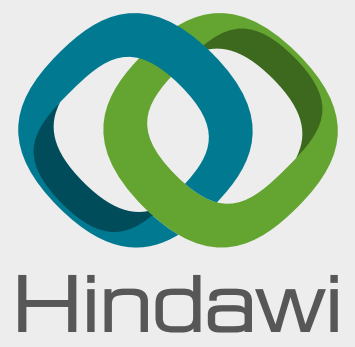

Submit your manuscripts at

www.hindawi.com
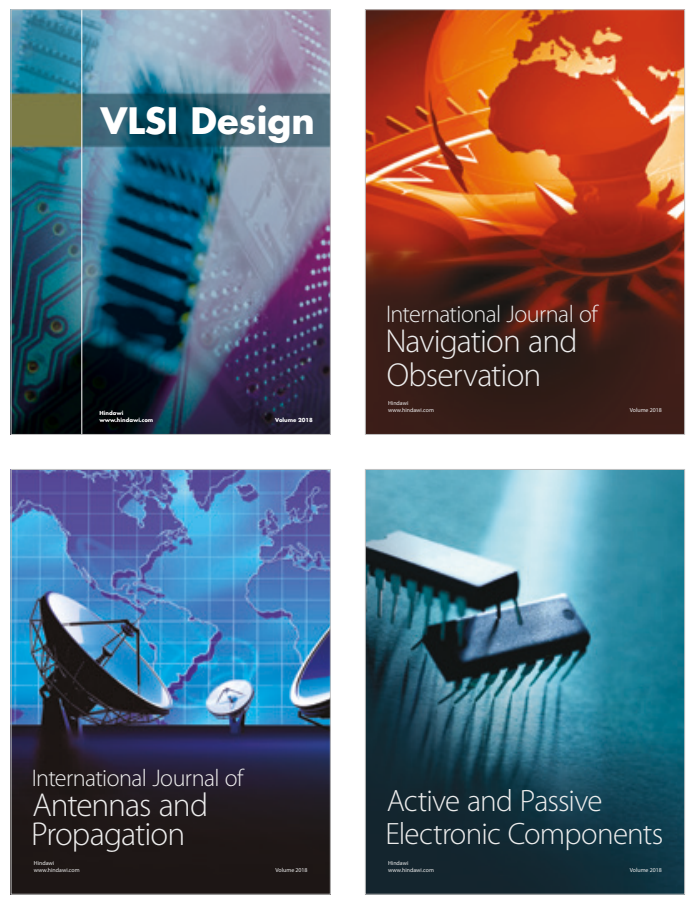
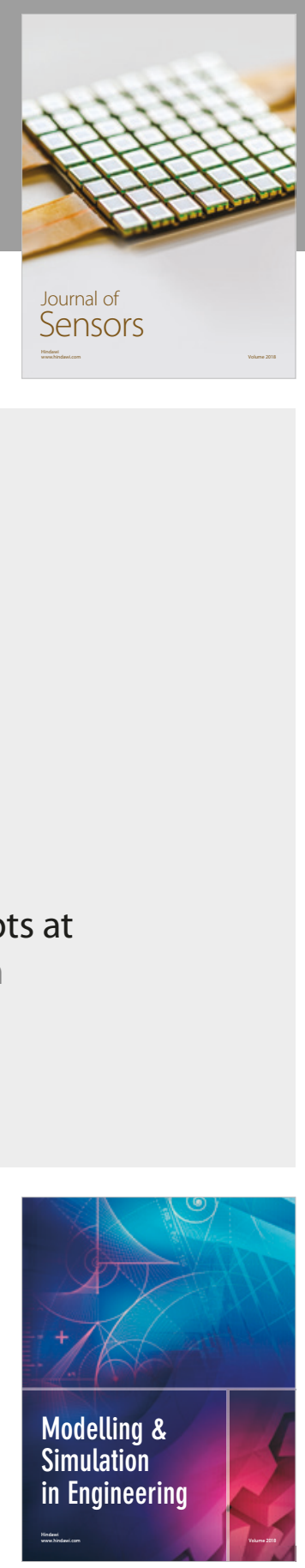

\section{Advances \\ Multimedia}
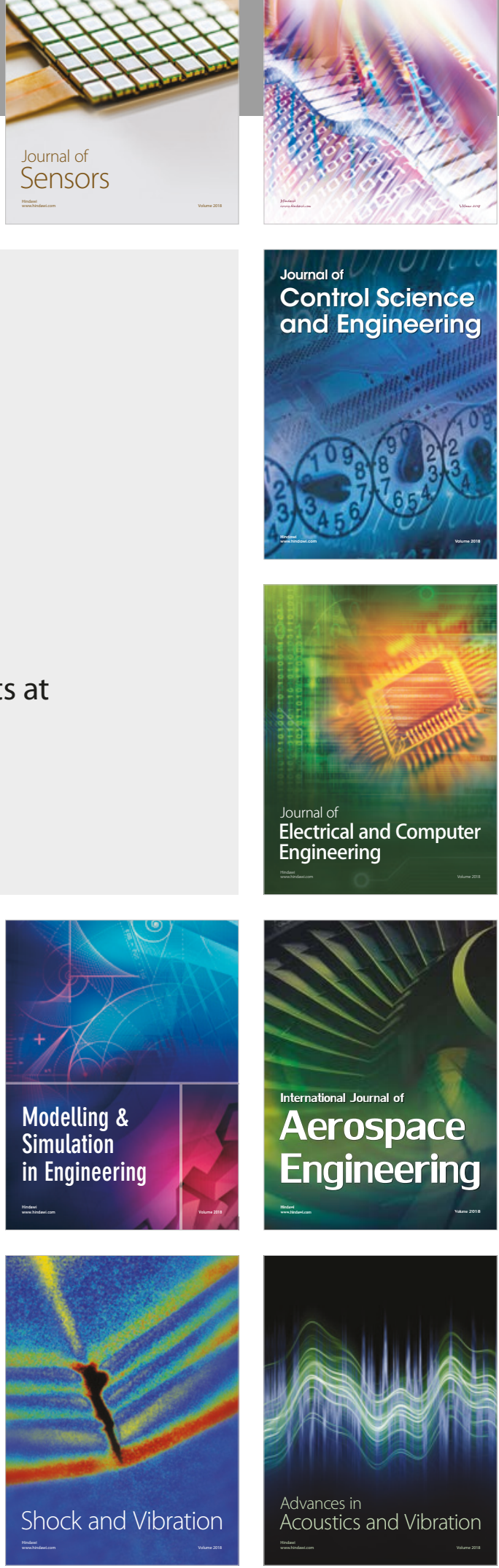